Progress in Research of Automobile Exhaust Purification

\title{
Chang Cui
}

School of Environmental Science and Engineering, North China Electric Power University, Baoding 071003, China

872243977@qq.com

Abstract: This paper summarizes the composition and harm of automobile exhaust gas. It also briefly marshals the development and main components of automobile exhaust purification catalysts, of which three way catalyst is emphatically introduced. In this paper, some problems existing in the current conversion technology are discussed, as well as the research trend of automobile exhaust purification catalysts in future.

Keywords:Automobile exhaust control, catalyst, development.

\section{Introduction}

With the growing population and improvement of people's living standard, automotive vehicle is playing an important role in transportation. Following shows the the number of cars in China in recent 5 years.

Table 1 Car ownership in China

\begin{tabular}{|c|c|c|c|c|c|}
\hline & 2015 & 2014 & 2013 & 2012 & 2011 \\
\hline private car capacity & $140,991,000$ & $123,393,600$ & $105,016,800$ & $88,386,000$ & $73,267,900$ \\
\hline civil car capacity & $162,844,500$ & $145,981,100$ & $126,701,400$ & $109,330,900$ & $93,563,200$ \\
\hline
\end{tabular}

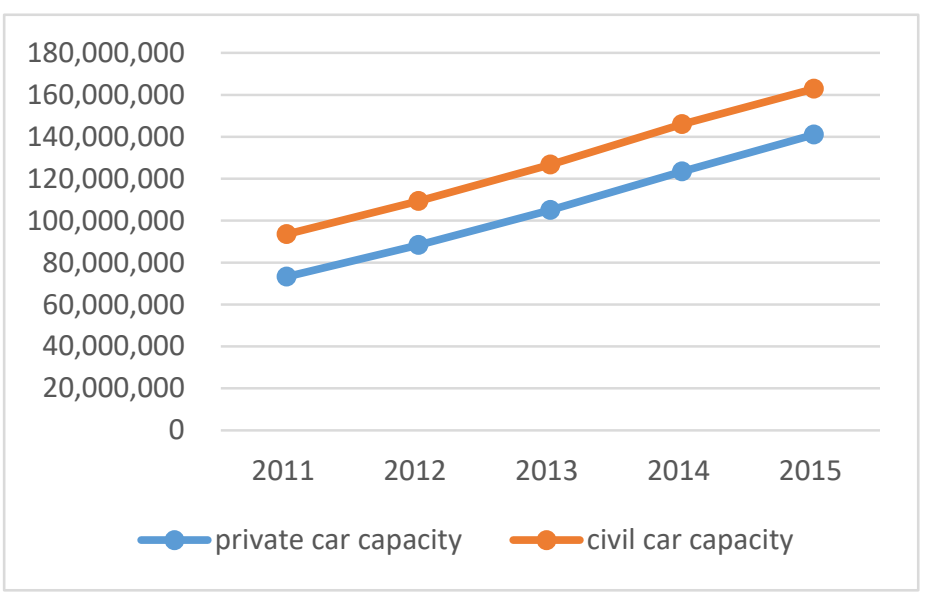

Fig. 1 Car ownership in China 
Over the five years, the numbers of cars in China almost doubled. The massive automotive vehicle emissions becomes one of the major contributors to urban air pollution. Automobile exhaust contains carbon monoxide(CO)、hydrocarbons(HC)、 nitrogen oxides $\left(\mathrm{NO}_{\mathrm{X}}\right)$ and particulate matters(PM). These pollutants not only bring about photochemical smog, acid rain and greenhouse effect, but also cause respiratory diseases. The purification processing of automobile exhaust is divided into internal and external, the later one is after treatment of exhaust gas, using automobile catalytic convertors and particulate filters to control the exhaust fumes. At present three-way catalyst system is used in the convertor and represents the most effective emission control method.

\section{Development of vehicle catalysts}

Advanced countries such as the United States and Japan are in the leading level in the research of automobile exhaust purification. The initial catalyst mainly utilized platinum(Pt) and palladium(Pb), focusing on the treatment of $\mathrm{CO}$ and $\mathrm{HC}$, while had almost no effect on the reduce of $\mathrm{NO}_{\mathrm{X}}$. Later, with the enhancement of public awareness towards environmental protection, Rh was introducted to remove $\mathrm{NO}_{\mathrm{X}}$, namely three-way catalyst. And laterly some representative rare earth elements were used as additives in catalyst such as lanthanum(La), cerium(Ce), zirconium(Zr) and barium(Ba), which has no catalytic activity or low activity but can improve the catalyst performance $^{[1]}$.

The initial monolith used in catalysts was Al2O3 globules. It was simple and cheap, with large surface area and high mechanical strength. But this monolith brought large exhaust resistance. Later, honeycomb support was applied, which provided uniform gas flow channels, showing smaller gas resistance, as well as higher mechanical strength and better thermal deformation behavior. Current honeycomb monolith material is divided into metal and ceramics, the former support uses cordierite as its basic raw material, coated with a layer of $\mathrm{y}$-Al2O3. A three-way catalyst converted automobile exhausted gas composed of $\mathrm{HC}, \mathrm{CO}$ and NOx into harmless components such as water $\left(\mathrm{H}_{2} \mathrm{O}\right)$, carbon dioxide(CO) and nitrogen $\left(\mathrm{N}_{2}\right)$. The conversion efficiency reached closely to $100 \%$ when the practical air-fuel ratio is near the theoretical value, which requires the accurate control of engine to keep air-fuel ratio in a narrow range. 


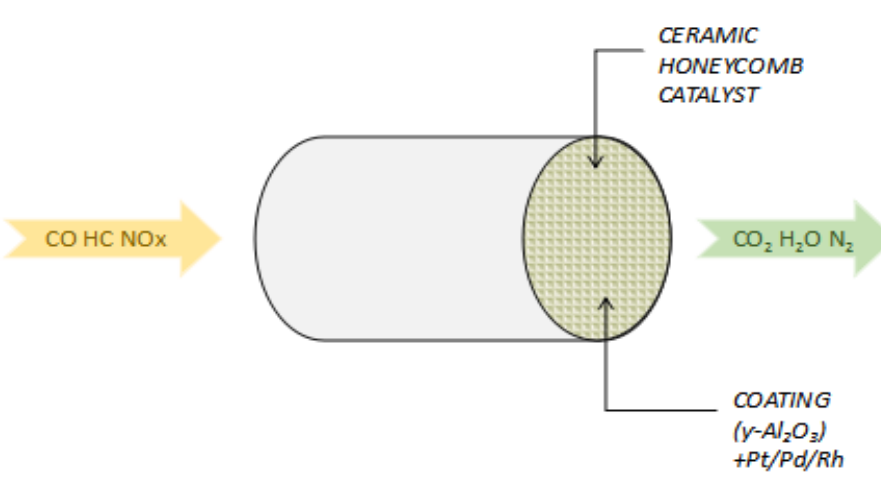

Fig. 2 Three-way Catalyst

In 1995, Ford company developed three-way pd-ycz catalyst, combining Pd with alkaline earth metal and rare earth oxides ${ }^{[2]}$.It showed similar catalytic activity to Rh when exposed at high temperature, but was susceptible to poisonous substance like $\mathrm{Pb}$ and $\mathrm{S}$. In the early 2000s, the Japanese company Daihatsu using nanotechnology developed a "super intelligent catalyst", in which Pt and Rh showed self regeneration. At present, some companies are committed to developing four-way catalyst, which increasing the capture of particles.

\section{Existing problems of three way catalysts}

At present, massive noble metals are utilized in catalysts to achieve a good catalytic effect, while there is no effective technology to recycle them. What's more, almost all kinds of catalysts use Pd as their active component, which is sensitive to toxicants such as $\mathrm{Pb}, \mathrm{S}$ and $\mathrm{P}$, and prone to sinter under the reducing atmosphere. Generally, a lot of toxic gases in the exhaust are produced during the cold start, because most catalyst show low initial catalytic activity at low temperatures and improper air-fuel ratios ${ }^{[3]}$.In addition, since the thermal stability of most catalysts is poor, the catalytic efficiency can not meet the design requirements at high temperatures, too.

For ceramic monolith, cordierite supportor and $\mathrm{y}$-Al2O3 coating has different thermal expansion coefficient, thus with the aging of catalyst, the coating layer will fall off the supporter, which greatly affects the catalytic conversion efficiency. As to mental monolith, its mechanical strength is higher than that of the ceramics, and the heat transfer performance is better, but its resistance to oxidation at high temperature is not good. And mantal catalyst's forming process is rather complex, which leads to high cost and limits it utilize in the field of industry enterprise.

\section{Conclusions}

At present, most of the three way catalysts applied in China are imported from other countries. But some domestic catalysts, composed of simple oxide catalysts, rare earth 
and noble metals, are now found to have highly catalytic activity with lower prise, which is hopeful to be commercially pushed ${ }^{[4]}$.

Metal ceramic (Cermet) is a new material that composed of metal and several ceramic phases. ZrO2 based cermet has good resistance to high temperature, abrasion and oxidation. It also has high mechanical strength. If utilized as catalyst monolith, it can combine the advantages of ceramic and metal monolith.

What's more, non-thermal plasma is now applied in air pollution control.

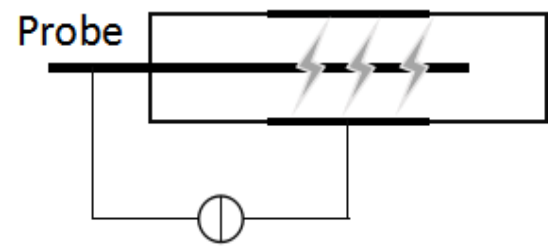

\section{Catalyst}

Fig. 2 Non-thermal Plasma Generator

First, by discharging through a probe in the plasma generator, the molecules are activated to form intermediate substances, which are to enter into the back catalytic reactor and be converted into harmless substances. In general, the use of it in treating low concentration exhaust gas is more energy saving and has high efficiency ${ }^{[5]}$. It's can effectively remove nitrogen oxides, promising to be used for automotive exhaust purification.

\section{References}

[1]TAN Jingming, WU kan. Research progress of three way catalysts[J]. Environment,2006,(S2):1-3. [2]HE Chongheng, WANG Ren, Advance and Development in Exhaust Gas Pollution and Control, Environmental Pollution \& Control,1996(3):17-21

[3]R.D.O’Sullivan et al.Platinum Metals Rev,1992,36(2):86

[4Tan Yuxin, Huang Chuanrong, Gan Shifan, Wang Yonggang. Research on a New Type of Catalyst for Automobile Exhaust Control[J].CHINESE JOURNAL OF ENVIROMENTAL SCIENCE,1998,(03):20-23.

[5]Zhang Guijian, Li Kai, LIN Qiang,NING Ping, TANG Lihong, WANG Fang, YUAN Qin. Research Progress of Removing Atmospheric Pollutants by Non-thermal Plasma Technology[J].Materials Review,2015,(01):137-142. 